\title{
İndüksiyonla Sertleştirilmiş AISI 52100 Rulman Çeliğinin Taşlanmasında İşleme Parametrelerinin Yüzey Pürüzlülüğü Üzerinde Etkisinin Deneysel Analizi
}

\author{
Ufuk Kabasakaloğlu ${ }^{1}$, Menderes Kam ${ }^{2 *}$ \\ Geliş / Received: 27/12/2019 \\ Revize / Revised: 15/03/2020 \\ Kabul / Accepted: 15/03/2020 \\ öZ \\ Taşlama işlemi, parçaların optimum yüzey kalitesi, ölçü tamlığında imal edilebilmesi ve yüksek sertliğe sahip \\ olan malzemeleri işlemek amacıyla yaygın olarak kullanılmaktadır. Ayrıca, taşlama işleminin nihai işlem \\ olmasından dolayı uygun işleme parametreleri seçilerek optimum değerlerin belirlenmesi büyük önem arz \\ etmektedir. Bu çalışmada, indüksiyonla yüzey sertleştirme işlemi uygulanmış AISI 52100 (100Cr6) rulman \\ çeliği iş parçalarının silindirik taşlama işleminde parametrelerin sertlik ve yüzey pürüzlülüğü üzerindeki \\ etkilerinin deneysel olarak incelenmesi amaçlanmıştır. Taşlama deneyleri; iki farklı taş (Alüminyum oksit - \\ AlO3 EKR 60 L4V, Silisyum karbür - SCG 60 K6V), iki farklı sertliğe sahip AISI 52100 rulman çeliği iş \\ parçası (56 ve $61 \mathrm{HRc}$ ) ve üç farklı kesme derinliği (100, 200, $300 \mu \mathrm{m})$ parametreleri kullanılarak \\ gerçekleştirilmiştir. Deneysel çalışmada silindirik taşlama işlemi uygulanmış iş parçalarının yüzey pürüzlülük \\ ölçümleri yapılmıştır. Sonuç olarak, artan kesme derinliği ile yüzey pürüzlülük değerlerinde önemli iyileşmeler \\ görülmüştür. En düşük yüzey pürüzlülüğü değerleri, Alüminyum oksit taşlama taşı ile $61 \mathrm{HRc}$ sertliğe sahip iş \\ parçasında elde edilmiştir.
}

Anahtar Kelimeler- AISI 52100, İndüksiyonla Sertleştirme, Sertlik, Taşlama, Yüzey Pürüzlülü̈̆̈̈̈

1İletişim: ufukkaba3@hotmail.com (https://orcid.org/0000-0002-8731-4955)

Makine Mühendisliği ABD, Fen Bilimleri Enstitüsü, Düzce Üniversitesi, Düzce, Türkiye.

2*Sorumlu yazar İletişim: mendereskam@duzce.edu.tr (https://orcid.org/0000-0002-9813-559X)

Makine ve Metal Teknolojileri, Dr. Engin PAK Cumayeri MYO, Düzce Üniversitesi, Düzce, Türkiye. 


\title{
Experimental Analysis of the Effect of Machining Parameters on Surface Roughness in Grinding of Induction Hardened AISI 52100 Bearing Steel
}

\begin{abstract}
The grinding process is widely used for optimum surface quality of parts, manufacturing accuracy, and processing materials with high hardness. Furthermore, it is of great importance to determine the optimum values by selecting the appropriate parameters because the grinding process is the final process. The aim of this study was to investigate the effects of grinding parameters on hardness and surface roughness in grinding of induction surface hardened AISI 52100 (100Cr6) bearing steel work pieces. Grinding experiments; two different stones (Alumina - A2O3 EKR 60 L4V and silicon carbide - SCG $60 \mathrm{~K} 6 \mathrm{~V}$ ), two different hardness AISI 52100 bearing steel work piece (56 and $61 \mathrm{HRc})$ and three different depth of cut $(100,200,300 \mu \mathrm{m})$ using parameters were selected. In the experimental study, surface roughness measurements of work pieces in cylindrical grinding process were carried out. As a result, significant improvements in surface roughness values were observed with increasing depth of cut. The lowest surface roughness values were obtained from the work piece $(61 \mathrm{HRc}$ hardness) with aluminium oxide grinding stone.
\end{abstract}

Keywords- AISI 52100, Induction hardening, Grinding, Hardness, Surface roughness. 


\section{GİRIŞ}

Endüstride bilimsel çalışmalarla birlikte yeni teknolojik gelişmeler yaşanmakta ve kullanılan ürünler de değişmektedir. Bu kapsamda, işleme tekniklerinin doğrudan veya dolaylı olarak etkilendiği işleme süreçleri bulunmaktadır. Bunların işleme sırasında birçok etkisi vardır, bu nedenle işleme parametrelerinin değerleri doğru belirlenmez ise istenen verilerde tam olarak elde edilemeyecektir. Bu bağlamda, rulman çelikleri; sertlik açısından yüksek karbonlu, yorulma dayanımı açısından ise metalürjik kalite çelikleridir. Rulmanlı yataklar, mekanik ekipmanlarda dönmeye imkân sağlamak ve ciddi yükleri taşımak için çokça kullanılan ve temel bir bileşen olarak birç̧ok dönen mekanizmada endüstriyel gelişime önemli ölçüde katkı sağlamaktadır [1]. AISI 52100 rulman çeliği; kollu kılavuzlarda, freze çakılarında, millerde, hassas parçalarda, burçlarda, yataklarda, rulman bileziğinde, bilyelerde, damgalama araçlarında, dişli takımlarda, kalıplarda, ölçü aletlerinde, pimlerde, sıkma bileziklerde, vidalarda, motor ve pompa parçalarında, anti sürtünme yataklarında, makaralarda ve hidrolik donanım parçalarında kullanımı yaygın olan bir çelik türüdür [2].

Taşlama işlemi, parçaların istenilen konum, şekil ve ölçü hassasiyetinde çıkmasını sağlayan en önemli imalat yöntemlerinden birisidir. Ayrıca, dönen taşlama taşı yüzeyindeki farklı kesme geometrilerine sahip aşındırıcı küçük tanelerin dönen iş parçasına temas noktasında yatay olarak baskı uygulayarak küçük miktarda talaş derinliğinde pasolar ile talaş kaldırılarak parçanın istenen hassas ölçülere getirilmesini sağlayan işlem olarak tanımlanmaktadır. İmalatta taşlama işlemi özellikle; ölçü tamlığı, dairesellik, yüzey kalitesi ve hassas toleransların istendiği havacılık, otomotiv, ulaşım, tıbbi cihazlar ve elektronik gibi birçok alanda yaygın olarak kullanılmaktadır. Bunun yanında ölçme aletleri, kızak ve kayıtlar, miller, dişli çarklar, merdane ve yatak bilezikleri gibi makine bileşenlerinin yüzeylerinin de hassas olması gereklidir. Aynı zamanda bu yüzeylerin korozyona karşı dayanıklı olabilmesi içinde taşlama işlemi uygulanmaktadır [3-7].

Literatürde, AISI 52100 rulman çeliğinin taşlanabilirliği ile ilgili yapılan birçok çalışma mevcuttur [512]. Ancak, indüksiyonla yüzey sertleştirme işlemi uygulanmış AISI 52100 rulman çeliğinin taşlanabilirliğinin deneysel incelenmesi ile ilgili literatürde sınırlı sayıda çalışma vardır. Günümüzde ise taşlama işlemi, imalat süreçlerinin en önemli aşamalarından biri olmuştur. Bu nedenle taşlama işleminde sağlanacak iyileşmeler sayesinde büyük maddi kazançlar elde edilebileceği düşünülmektedir.

İmalatta, taşlama işleminin son işlem olması nedeniyle uygun parametreler seçilerek optimum değerler elde edilmesi büyük önem arz etmektedir. Bununla birlikte yüksek verimlilikle, az maliyetle ve kısa sürede kabul edilebilecek yüzey kalitelerinin elde edilebilmesi uygun işleme parametreleri seçimi ile mümkündür. Uygun belirlenmeyen parametreler ise taşlama taşlarının çatlaması veya kırılması, hızlı aşınması ve yanması gibi ekonomik kayıpların yanında, parçaların zarar görmesi veya tekrar işleme gerek duyulması, yüzey kalitesinin bozulması gibi maddi kayıp ve çok zaman harcanmasına sebep olmaktadır. Diğer yandan sertleştirilmiş parçalarında taşlanması gerekmektedir. Sertleștirme işlemi uygulanmış parçaların çalışma şartları göz önüne alındığında, tamamen sertleştirilmesinin istendiği durumlarla birlikte, bazen gerekli kısımlarının sertleştirilmesi de talep edilmektedir. Genel olarak makine bileşenlerinin aşınmaması gereken yüzeylerin sertleştirilmesine ihtiyaç duyulmaktadır. Özellikle, darbeli ve vuruntulu çalışma koşulları için çeliğin çekirdeğine kadar sertleşmemesi daha uygun olmaktadır. Bu sebeple çelik malzemeler, yalnız yüzeyinin sertleştirilmesi yani ince bir katmanın (sertlik derinliği) sertleştirilmesi ile çalışma koşulları için uygun olarak hazırlanırlar ve bu işleme de yüzey sertleştirilmesi adı verilmektedir. Yüzey sertleştirme uygulamaları ile aşınma dayanımının artııılması ile eğme, bükme gibi tekrarlı yüklemelere maruz parçalarda yorulma dayanımı artırılabilmektedir. İnce cidarlı, değişik kesitli parçalarda çarpılma veya sertleştirme (su verme) çatlamaları riski en aza indirilmektedir. Aşınma dayanımı yüksek, teknik öneme sahip parçalarda aranan, merkez bölgesinde yüksek bir mukavemet, yanında yeterli derecede tokluk ve sünekliğe sahip olma beklentisi yerine getirilmektedir. Parçalardan beklenen işleve göre, bu iyileştirmelerden birisi ön plana çıkabilmekte, uygulanacak yüzey işlemi ve işleme ilişsin parametreler de buna göre tayin edilmektedir. Yüzey bölgesinin teknik özelliklerini değiştirmek için başvurulan yüzey sertleştirme yöntemleri parçadan beklenen fonksiyona, mevcut malzemenin bileşimine, parçanın hassasiyetine ve göze alınan maliyete bağlı olarak seçilmektedir [7-12]. Bu bağlamda, indüksiyonla sertleştirme işlemi son yıllarda metallerin özelliklerini iyileştirmek için kullanılan 1 ssıl işlem yöntemlerinden birisidir. İndüksiyonla sertleştirilmiş ve hassas taşlanmış miller endüstrinin birçok alanında özellikle otomotiv sektöründe yaygın olarak kullanılmaktadır. Millerden istenilen, yükleri taşımanın yanı sıra sorunsuz bir şekilde ömürlerini tamamlamalarıdır. İndüksiyonla sertleştirme işlemi, sementasyon ile elde edilemeyen uygun çekirdek özellikleri, 
yüksek sertlik derinliği gibi özelliklerin elde edilebilmesi amacıyla kullanılmaktadır. Yüksek torkla çalışması sebebiyle fazla sertlik verilemeyen millerin aşınma dayanımı gerektiren kısımların indüksiyonla sertleştirilmesi örnek olarak verilebilir [13-15]. İndüksiyonla sertleştirme işlemi ve farklı 1sıl işlemler uygulanmış miller ile ilgili birçok deneysel çalışma yapılmıştır [16-22].

Yüzey pürüzlülüğü; sadece aşınma, yorulma, sürtünme ve yağlama gibi tribolojik olarak değil aynı zamanda sıdırmazlık, elektrik, 1sı iletimi vb. gibi farklı alanlarda da dikkate alınması gereken önemli bir etkendir. $\mathrm{Bu}$ nedenle makine bileşenlerinde yüzey pürüzlülük değerlerinin belirlenmesi çok önemlidir. Bu kapsamda, maksimum tepe-çukur yüksekliği (Rt), ortalama yüzey pürüzlülük değeri (Ra) ve on nokta yüksekliği (Rz) gibi pürüzlülük parametreleri ölçülebilir. Bu pürüzlülük parametrelerinden en yaygın kullanılanı, dünya çapında kabul görmüş ve ülkemizde de kullanılan Ra'dır [12].

Silindirik taşlama taşlarını oluşturan tanelerin taş üzerinden sökülebilme özelliğine göre tanelerin birbirine olan bağlantı kuvvetine sertlik denir. Taşlama taşı talaş kaldırma yaparken taşı oluşturan aşındırıcı taneler birleştirme aracı tarafından kolayca bırakılıyor veya aşındırıcı tane yerinden kolayca çıkmıyorsa buna yumuşak taşlama taşı denir. Aşındırıcı taneler yuvasını kolayca çıkmıyor veya birleştirme aracı aşındırıcı taneyi kolayca bırakmıyorsa buna da sert taşlama taşı denir. Bundan dolayı genel olarak malzemelerin cinsine göre yumuşak ya da sert taşlama taşı seçimi yapılmaktadır [4-6].

Bu çalışmada, indüksiyonla yüzey sertleştirilmiş AISI 52100 (56 ve 61 HRc) rulman çeliğinin silindirik taşlanmasında parametrelerinin ortalama yüzey pürüzlülüğü $(\mathrm{Ra})$ ve sertlik (HRc) üzerindeki etkilerin ortaya konulması, uygun parametre ve taş seçimi ile taşlanan iş parçasının yüzey kalitesinin arttırılması amaçlanmıştır.

\section{MATERYEL VE METOT}

Bu çalışmada, indüksiyonla yüzeyleri sertleştirilmiş AISI 52100 rulman çeliği iş parçalarının taşlama işleminde işleme parametrelerinin sertlik ve yüzey pürüzlülüğüne etkileri deneysel olarak incelenmiştir. Deneylerde kullanılan AISI 52100 (100Cr6) rulman çeliğinin kimyasal bileşimi (\%) Tablo 1'de verilmiştir. AISI 52100 rulman çeliği (Çap 20x300 mm) iş parçalarına indüksiyonla yüzey sertleştirme işlemi uygulanmış ve yüzey sertlikleri $56 \mathrm{HRc}$, $61 \mathrm{HRc}$ değerine getirilmiş ve iş parçası üzerinde sertlik derinlikleri $3 \mathrm{~mm}$ olarak ölçülmüştür.

Tablo 1. Deneylerde kullanılan AISI 52100 (100Cr6) rulman çeliğinin kimyasal bileşimi

\begin{tabular}{cccccccccl}
\hline \hline Element & $\mathrm{C}$ & $\mathrm{Si}$ & $\mathrm{Mn}$ & $\mathrm{P}$ & $\mathrm{S}$ & $\mathrm{Cr}$ & $\mathrm{Mo}$ & $\mathrm{Al}$ & $\mathrm{Fe}$ \\
\hline$(\%)$ & 0,973 & 0,27 & 0,33 & 0,016 & 0,001 & 1,41 & 0,02 & 0,025 & Kalan \\
\hline \hline
\end{tabular}

Taşlama deneyleri; iki farklı taş (Alüminyum oksit - Al2O3 EKR 60 L4V, Silisyum karbür - SCG 60 K6V), indüksiyonla yüzeyleri sertleştirilmiş AISI 52100 çeliği iş parçaları (56 ve $61 \mathrm{HRc}$ ) ve üç farklı kesme derinliği $(100,200,300 \mu \mathrm{m})$ parametreleri kullanılarak Şekil 1'de verilen silindirik taşlama tezgâhında (SMARC M1432B/1500) gerçekleştirilmiştir. Deneylerde kullanılan silindirik taşlama tezgâhının teknik özellikleri ise Tablo 2'de verilmiştir. 

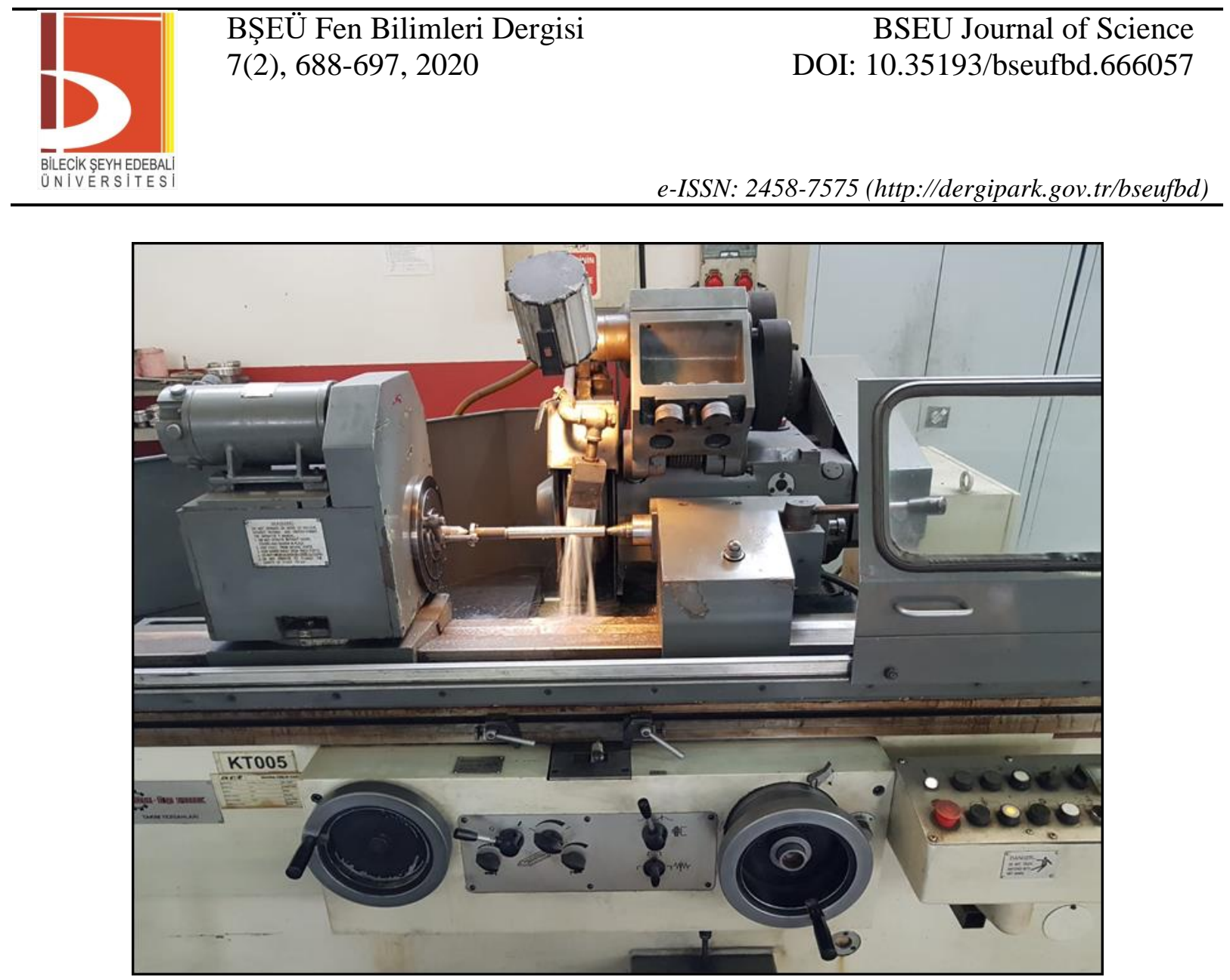

Şekil 1. Silindirik taşlama tezgâhı

Tablo 2. Silindirik taşlama tezgâhının teknik özellikleri

\begin{tabular}{ll}
\hline \multicolumn{2}{c}{ Teknik Özellikler } \\
\hline Toplam tezgâh gücü & $5,5 \mathrm{~kW}$ \\
\hline İş mili devri & $1500 \mathrm{dev} / \mathrm{dak}$ \\
\hline Taşlama uzunluğu & $1500 / 125 \mathrm{~mm}$ \\
\hline $\begin{array}{l}\text { Maksimum bağlanabilecek } \\
\text { parça uzunluğu }\end{array}$ & $8-30 / 100-320 \mathrm{~mm}$ \\
\hline İş tablası hızı & $0,1-4 \mathrm{~m} / \mathrm{dak}$ \\
\hline
\end{tabular}

Taşlama deneylerinde AISI 52100 rulman çeliği iş parçalarının taşlanmasında kullanılan parametreler, kesme hızı, ilerleme ve kesme derinlikleri dikkate alınarak belirlenmiştir. İndüksiyonla sertleştirme işlemi uygulanmış AISI 52100 çeliğinin taşlanabilirliğinin incelenmesi amacıyla kullanılan taşlama parametreleri Tablo 3'de verilmiştir. 
Tablo 3. Taşlama parametreleri

\begin{tabular}{|c|c|}
\hline \multicolumn{2}{|r|}{ Taşlama parametreleri } \\
\hline $\begin{array}{l}\text { Deney numuneleri } \\
\text { ( } 2 \text { Adet) }\end{array}$ & $\begin{array}{l}\text { İndiksiyonla yüzeyleri sertleştirilmiş AISI } 52100 \text { (100Cr6) rulman çeliği iş parçaları (Sertlik derinliği } \\
3 \mathrm{~mm}) \\
\text { Çap 20x300 mm ( } 56 \mathrm{HRc} \text { ve } 61 \mathrm{HRc})\end{array}$ \\
\hline $\begin{array}{l}\text { Taşların cinsi } \\
\text { ( } 2 \text { Adet })\end{array}$ & $\begin{array}{l}\text { Alüminyum oksit-EKR } 60 \mathrm{~L} 4 \mathrm{~V} \text {, } \\
\text { Silisyum karbür -SCG } 60 \mathrm{~K} 6 \mathrm{~V}\end{array}$ \\
\hline $\begin{array}{l}\text { Taşlama taşı } \\
\text { boyutları (mm) }\end{array}$ & $\begin{array}{l}400 \times 20 \\
50 \times 203.2\end{array}$ \\
\hline $\begin{array}{l}\text { Kesme derinliği } \\
(\mu \mathrm{m})\end{array}$ & $100,200,300$ \\
\hline Tabla hızı (m/dak) & 0.12 \\
\hline $\begin{array}{l}\text { İş parçası devir } \\
\text { sayısı (dev/dak) }\end{array}$ & 135 \\
\hline
\end{tabular}

Tablo 3'de taşların cinsi Alüminyum oksit - EKR 60 L4V, Silisyum karbür - SCG 60 K6V olarak verilmiştir. Taşların sertlikleri Alüminyum oksit taş için L orta sertlikte ve Silisyum karbür taş için ise yumuşak sertlikte olan K olarak verilmiştir. Taşların tane boyutları ise 60 normal tane boyutlarına sahiptir. Bu deneysel çalışmada, tüm taşlama deneyleri soğutma sıvısı kullanılarak gerçekleştirilmiştir. Taşlama deneylerinde; her iş parçası $300 \mathrm{~mm}$ taşlama mesafesinde iki gidiş geliş olacak şekilde ve belirlenen parametreler kullanılarak silindirik taşlama işlemi uygulanmıştır. Ayrıca, taşlama taşlarının bilenmesi için tek taneli bileme elması kullanılmış ve her taşlama deneyi yapıldıktan sonra aynı şartlarda aynı bileme yöntemi kullanılarak taşlama taşı bileme elması ile $0,02 \mathrm{~mm}$ pasolarla $4 \mathrm{kez}$ gidip gelerek bilemi işlemi yapılmıştır.

Silindirik taşlama deneyleri uygulanan AISI 52100 rulman çeliği iş parçalarının yüzey pürüzlülüğü ölçümleri Taylor Hobson marka Talysurf PGI 830 form ve pürüzlülük cihazında gerçekleştirilmiştir. Yüzey pürüzlülük cihazı ile ölçümü Şekil 2'de gösterilmiştir. Her numune için üçer adet ölçüm yapılarak elde edilen verilerin aritmetik ortalamaları alınmış ve ortalama yüzey pürüzlülüğü değerleri elde edilmiştir.

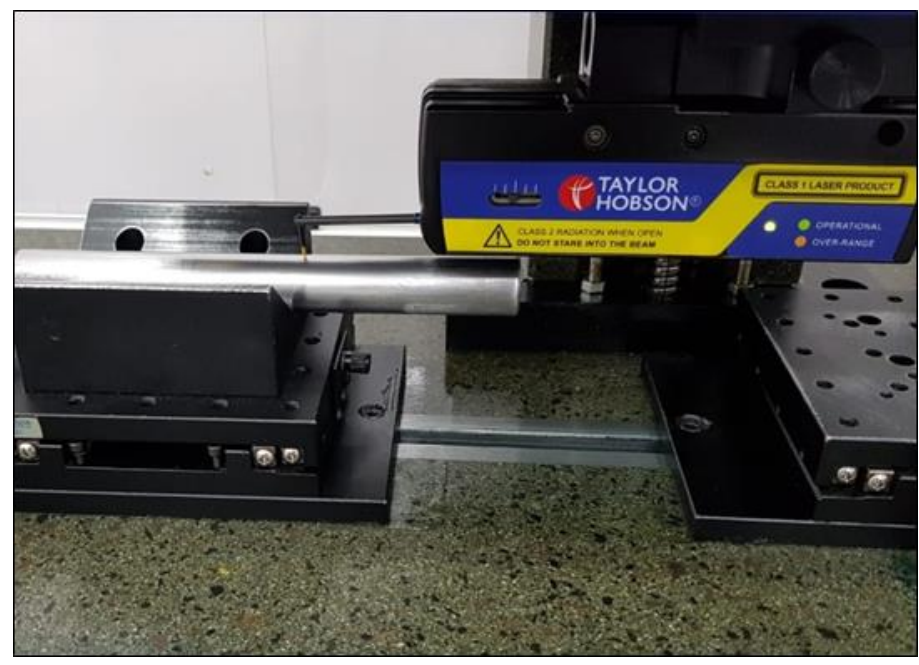

Şekil 2. Yüzey pürüzlülük ölçümü 


\section{BULGULAR VE TARTIŞMA}

Silindirik taşlama deneyleri sonucunda elde edilen yüzey pürüzlülüğü değerleri (Ra, Rz ve Rt) Tablo 4 ve Tablo 5'te verilmiştir. Elde edilen bulgulardan ortalama yüzey pürüzlülüğü (Ra) değerleri (56 HRc) Şekil 3'te ve ortalama yüzey pürüzlülüğü $(\mathrm{Ra})$ değerleri $(61 \mathrm{HRc})$ Şekil 4'da grafik olarak gösterilmiştir. Bulgulara göre, yüzey sertlik değeri yüksek olan iş parçasında daha iyi yüzey kalitesi ve dolayısı ile daha düşük yüzey pürüzlülüğü değerleri elde edilmiştir. Bununla birlikte sertliğin artmasından dolayı iş parçalarının taşlanabilirliği iyileşmiştir. Sertliğin artması ile taşlanabilirliğin iyileşmesi, aynı kesme şartları altında sert malzemelerde yumuşak malzemelere göre daha iyi yüzey kalitesinin elde edilmesi ile ilişkilendirilmiştir [12]. Kesme derinliği arttıkça parçalarda daha düşük Ra değerleri elde edilmiştir. Artan kesme derinliği ile yüzey pürüzlülük değerlerinde önemli iyileşmeler görülmüştür. Silindirik taşlama deneylerinde taşları (Alüminyum oksit - EKR 60 L4V, Silisyum karbür - SCG 60 K6V) karşılaştırdığımızda, Alüminyum oksit taşlama taşı ile yapılan deneylerde elde edilen Ra değerlerinin Silisyum karbür taşlama taşı ile yapılan taşlama deneylerinde elde edilen yüzey pürüzlülük değerlerinden daha düşük olduğu görülmüştür. Alüminyum oksit taşlama taşı ile daha pürüzsüz yüzeylerin elde edilebildiği görülmüştür. Bu durum, Alüminyum oksit taşlama taşının 1sıl iletkenliğinin Silisyum karbür taşlama taşının ısıl iletkenliğinden daha büyük olması ile ilişkilendirilebilir. Talaş kaldırma işlemlerinde kesici takım veya iş parçası malzemesinin termal iletkenliğinin yüksek olması, kesme esnasında kesme bölgesinde oluşan yüksek ısıların daha çabuk ve kolay uzaklaştırılması anlamına geleceğinden özellikle taşlama işleminde işlenen yüzeylerde daha düşük yüzey pürüzlülüğü değerleri elde edilebilmektedir. Bu durum, literatürde yapılan çalışmalarda tespit edilmiştir $[9,16]$.

Tablo 4. Taşlama deneyleri yüzey pürüzlülüğü değerleri (56 HRc)

\begin{tabular}{|c|c|c|c|c|}
\hline \multirow[b]{2}{*}{ Taşın Cinsi } & \multirow[b]{2}{*}{ Kesme Derinliği $(\mu \mathrm{m})$} & \multicolumn{3}{|c|}{ Yüzey Pürüzlülük Değerleri $(\mu \mathrm{m})$} \\
\hline & & $\mathbf{R a}$ & $\mathbf{R t}$ & $\mathbf{R z}$ \\
\hline \multirow{3}{*}{$\begin{array}{l}\text { Alüminyum oksit } \\
\mathrm{Al}_{2} \mathrm{O}_{3} \text { EKR } 60 \mathrm{~L} 4 \mathrm{~V}\end{array}$} & 100 & 0,470 & 4,103 & 2,305 \\
\hline & 200 & 0,357 & 3,633 & 1,847 \\
\hline & 300 & 0,322 & 2,532 & 1,618 \\
\hline \multirow{3}{*}{$\begin{array}{l}\text { Silisyum karbür } \\
\text { SCG } 60 \mathrm{~K} 6 \mathrm{~V}\end{array}$} & 100 & 0,579 & 4,928 & 2,736 \\
\hline & 200 & 0,727 & 5,935 & 3,380 \\
\hline & 300 & 0,527 & 3,740 & 2,575 \\
\hline
\end{tabular}

Tablo 5. Taşlama deneyleri yüzey pürüzlülüğü değerleri (61 HRc)

\begin{tabular}{|c|c|c|c|c|}
\hline \multirow{2}{*}{ Taşın Cinsi } & \multirow{2}{*}{ Kesme Derinliği $(\mu \mathrm{m})$} & \multicolumn{3}{|c|}{ Yüzey Pürüzlülük Değerleri $(\mu \mathrm{m})$} \\
\hline & & $\mathbf{R a}$ & Rt & $\mathbf{R z}$ \\
\hline \multirow{3}{*}{$\begin{array}{l}\text { Alüminyum oksit } \\
\mathrm{Al}_{2} \mathrm{O}_{3} \text { EKR } 60 \mathrm{~L} 4 \mathrm{~V}\end{array}$} & 100 & 0,350 & 3,300 & 2,053 \\
\hline & 200 & 0,296 & 2,645 & 1,694 \\
\hline & 300 & 0,349 & 2,616 & 1,835 \\
\hline \multirow{3}{*}{$\begin{array}{l}\text { Silisyum karbür } \\
\text { SCG } 60 \mathrm{~K} 6 \mathrm{~V}\end{array}$} & 100 & 0,667 & 5,612 & 3,290 \\
\hline & 200 & 0,550 & 4,557 & 2,995 \\
\hline & 300 & 0,589 & 4,703 & 3,177 \\
\hline
\end{tabular}




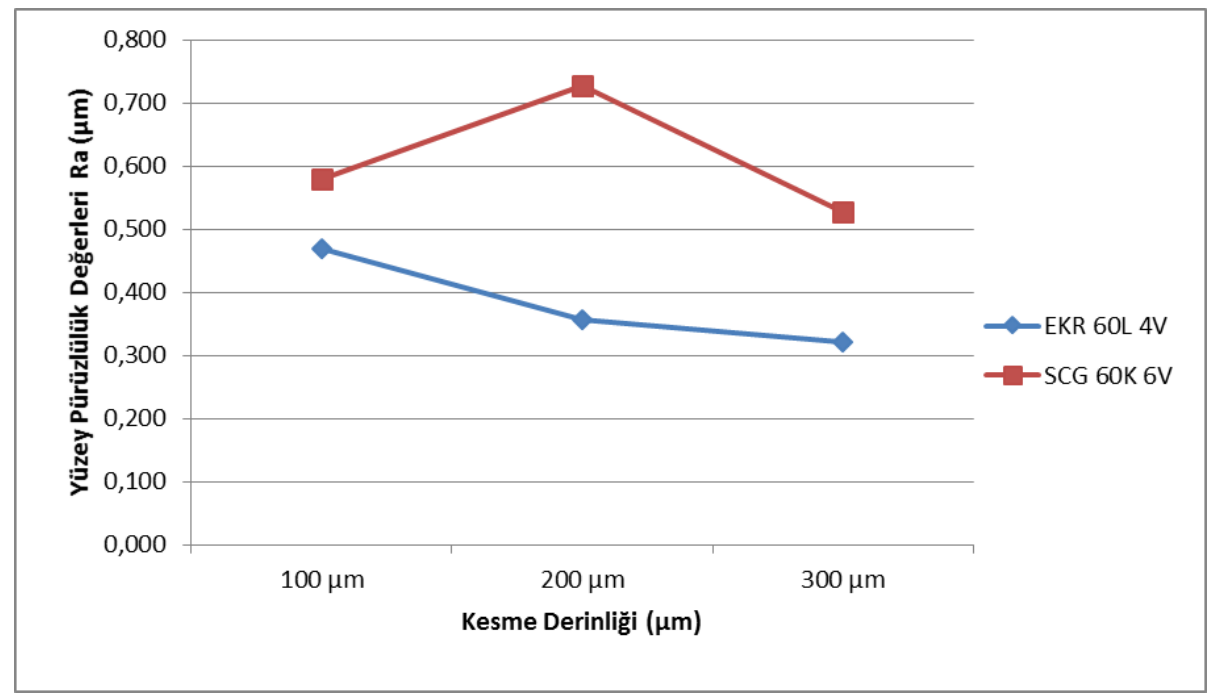

Şekil 3. Ortalama yüzey pürüzlülüğü $(\mathrm{Ra})$ değerleri, $56 \mathrm{HRc}(\mu \mathrm{m})$

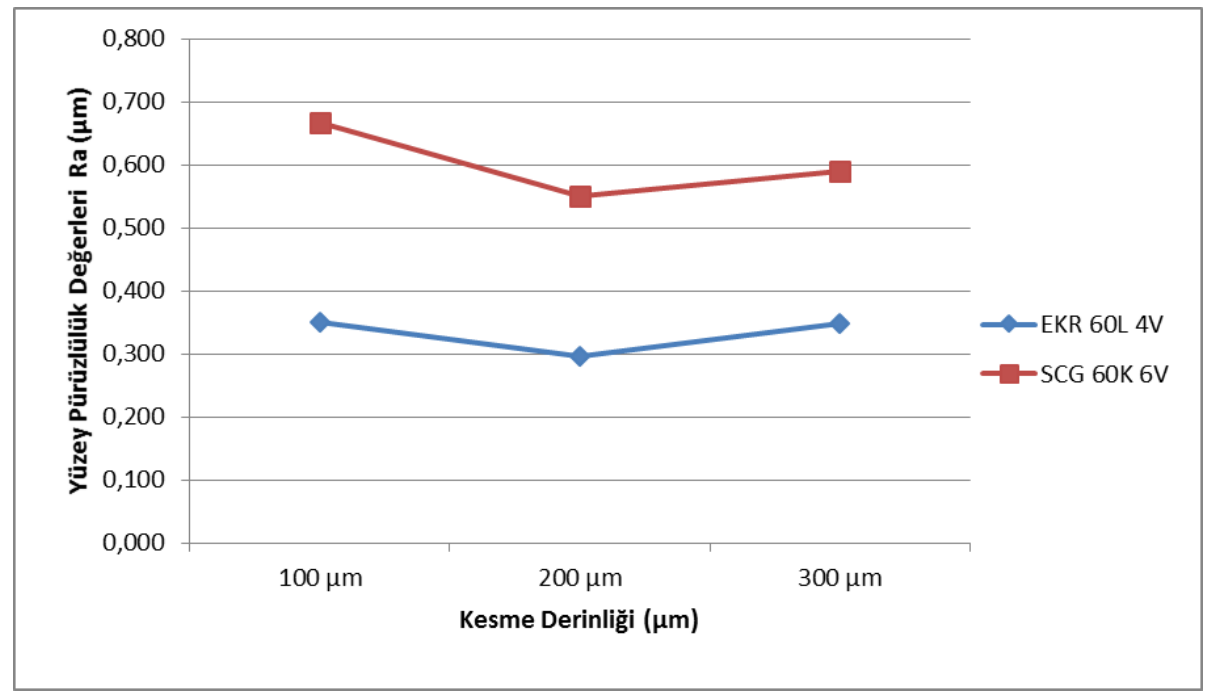

Şekil 4. Ortalama yüzey pürüzlülüğü $(\mathrm{Ra})$ değerleri, $61 \mathrm{HRc}(\mu \mathrm{m})$

Taşlama deneylerinde her iki yüzey sertliğine sahip iş parçasında (56 ve $61 \mathrm{HRc}$ ) taşlama taşı sertliğinin yüzey pürüzlülüğü oluşumunda önemli derecede etkili olduğu görülmüştür. Taş sertliğinin artması ile yüzey pürüzlülük değerlerinde de artış olduğu görülmüştür. En yüksek "Ra" değeri 56 HRc yüzey sertlik değerine sahip iş parçasında ve $200 \mu \mathrm{m}$ kesme derinliğinde Silisyum karbür taş ile $0,727 \mu \mathrm{m}$ yüzey pürüzlülüğü değeri bulunmuştur. En düşük "Ra" değeri ise 61 HRc yüzey sertlik değerine sahip iş parçasında ve $200 \mu \mathrm{m}$ kesme derinliğinde Alüminyum oksit taşlama taşı ile 0,296 $\mu \mathrm{m}$ elde edilmiştir. Yukarıda bahsedildiği gibi taşlama sürecinde yüksek sertlik değerlerine sahip iş parçasında daha düşük yüzey pürüzlülüğü değerleri elde edilebildiği görülmüştür. Bununla birlikte Tablo 4 ve Tablo 5'te verilen Rz ve Rt değerlerinin de Ra değerlerini doğrular nitelikte olduğu gözlenmiştir. Ayrıca, Taşlama işlemlerinde kullanılan her iki taşında tane sayılarının aynı 
olduğu göz önünde bulundurduğumuzda yumuşak sertlikteki taşa göre orta sertlikteki taş ile daha düşük yüzey pürüzlülük değerlerinin elde edilebildiği gözlenmiştir.

\section{SONUÇLAR ve ÖNERILER}

İndüksiyonla yüzey sertleştirme işlemi uygulanmış AISI 52100 rulman çeliği iş parçalarının silindirik taşlanması işleminde parametrelerin sertlik ve yüzey pürüzlülüğü üzerindeki etkileri deneysel olarak analiz edilmiş ve elde edilen sonuçlar aşağıda maddeler halinde verilmiştir.

- Taşlama işlemlerinde her iki yüzey sertliğine sahip iş parçasında (56 ve $61 \mathrm{HRc}$ ) taşlama taşı sertliğinin yüzey pürüzlülüğünü önemli derecede etkilediği tespit edilmiştir.

- Taşlama işlemlerinde yumuşak sertlikteki taşa göre orta sertlikteki taş ile daha düşük yüzey pürüzlülük değerlerinin elde edilebildiği gözlenmiştir.

- 56 HRc yüzey sertliğine sahip AISI 52100 iş parçasında, "Alüminyum oksit" taşlama taşı ile elde edilen yüzey pürüzlülük değerlerine oranladığımızda, "Silisyum karbür" taşlama taşı ile elde edilen yüzey pürüzlülük değerleri yaklaşı olarak \% 35 daha yüksek çıkmıştır.

- 61 HRc yüzey sertliğine sahip AISI 52100 iş parçasında, "Alüminyum oksit” taşlama taşı elde edilen yüzey pürüzlülük değerlerine oranladığımızda, "Silisyum karbür”" taşlama taşı ile elde edilen yüzey pürüzlülük değerleri \% 40 daha yüksek çıkmıştır.

- Silindirik taşlama işlemlerinde, yüksek sertlik değerlerine sahip iş parçalarında daha pürüzsüz yüzeyler elde edilebildiği bulunmuştur.

- En düşük Ra değerleri ise $61 \mathrm{HRc}$ yüzey sertlik değerine sahip iş parçasında ve $200 \mu \mathrm{m}$ kesme derinliğinde Alüminyum oksit taşlama taşı ile $0,296 \mu$ m olarak elde edilmiştir.

- En yüksek Ra değeri ise 56 HRc sertlik değerine sahip iş parçasında ve $200 \mu \mathrm{m}$ kesme derinliğinde Silisyum karbür taşlama taşı ile $0,727 \mu \mathrm{m}$ olarak bulunmuştur.

\section{KAYNAKLAR}

[1] Tonicello, E., Girodin, D., Sidoroff, C., Fazekas, A., \& Perez, M. (2012). Rolling bearing applications: some trends in materials and heat treatments, Materials Science and Technology, vol. 28, pp. 23-26.

[2] Ballıkaya, H. (2011). 100Cr6 Çeliğinin Teğetsel Tornalama-Frezeleme Yöntemi İle İşlenmesinde Kesme Parametrelerinin Deneysel Araştırılması, Yüksek Lisans Tezi, Fırat Üniversitesi Fen Bilimleri Enstitüsü, Elazı̆̆,

[3] Shah, S. M. A. (2011). Prediction of residual stresses due to grinding with phase transformation", PhD. Thesis, Institut National Des Sciences Appliquees De Lyon, Lyon, France.

[4] Gavas, M., Yaşar, M., Aydın, M., \& Altunpak, Y. (2013). Üretim Yöntemleri ve İmalat Teknolojileri, Üçüncü bask1, Seçkin Yayıncılık, Ankara.

[5] Demir, H., \& Güllü, A. (2001).Taşlamada Parametrelerin Etkisi, Pamukkale Üniversitesi Mühendislik Bilimleri Dergisi, 7(2), 189-198.

[6] Demir, H., \& Güllü, A. (2008). Taş dokusunun yüzey pürüzlülüğü ve taşlama kuvvetlerine etkilerinin incelenmesi, Gazi Üniversitesi Mühendislik-Mimarlık Fakültesi Dergisi, 23(1). 
[7] Tonshoff, H. K., Friemuth, T., \& Becker, J.C. (2002). Process monitoring in grinding, Annals of the CIRP, vol. 51, no. 2, pp. 551-571.

[8] Bhaduri, D., \& Chattopadhyay, A. K. (2010). Effect of pulsed DC CFUBM sputtered TiN coating on performance of nickel electroplated monolayer cBN wheel in grinding steel, Surface and Coatings Technology, vol. 204, no. 23, pp. 3818-3832.

[9] Demirci, A. H. (2004). Mühendislik malzemeleri: önemli endüstriyel malzemeler ve ısıl işlemleri, Aktüel yayınlarl, 25, 74-75.

[10] Atakök, G. (2008). CNC tornada talaş kaldırma işlemlerinde talaş kırıcı geometrisinin işlenebilirliğe etkilerinin deneysel ve sonlu elemanlar yöntemiyle incelenmesi, Doktora Tezi, Marmara Üniversitesi Fen Bilimleri Enstitüsü, İstanbul.

[11] Kurt, M., Köklü, U., Atakök, G., \& Bakır, B. (2012). An Experimental and Statistical Investigation on Shape Error in Interrupted Grinding", International Journal of Natural and Engineering Sciences, vol. 1, pp. 77-81.

[12] Khan, A. A., Ndaliman, M. B., Md. Soot, H. B. \& Ishak, N. B. (2012). Influence of thermal conductivity of electrodes on EDM process parameters", Aust. J. Basic Appl. Sci., vol. 6, no. 9, pp. 337-345.

[13] Metal Handbook, Heat Treating, 9th ed., Ohio, 1985.

[14] Duran M. C. (2016). 100Cr6 çeliğinden burç imalatında indüksiyonla yüzey sertleştirme uygulaması ve aşınma davranışlarının incelenmesi, Yüksek Lisans Tezi, Balıkesir Üniversitesi Fen Bilimleri Enstitüsü, Balıkesir.

[15] Altınel K. (2015). Rot başlarında indüksiyon yüzey sertleştirme işleminin ömür ve mekanik kuvvet dayanımına etkisi, Yüksek Lisans Tezi, Niğde Üniversitesi Fen Bilimleri Enstitüsü, Niğde.

[16] Kabasakaloğlu U. (2018). İndüksiyonla sertleştirilmiş millerin dinamik davranışlarının deneysel analizi, Yüksek Lisans Tezi, Düzce Üniversitesi Fen Bilimleri Enstitüsü, Düzce.

[17] Kabasakaloğlu U. \& Saruhan, H. (2019). Effects of induction hardened surface depth on the dynamic behavior of rotating shaft systems, Materials Testing, vol. 61, no: 3, pp. 277-281.

[18] Kam, M., Saruhan, H., \& Kabasakaloğlu, U. (2016). Experimental investigation of vibration generated from the cryogenic treated and induction surface hardened rotating shafts, $3^{\text {rd }}$ International Symposium on Railway Systems Engineering (ISERSE'16), 142-148.

[19] Kam, M., Saruhan, H., \& Guney, T. (2016). Kriyojenik işlem ve sıcak dövme işlemi uygulanmış millerin deneysel titreşim analizi. İleri Teknoloji Bilimleri Dergisi, 5(3), 21-30.

[20] Alçelik, N. \& Kam, M. (2020). Dönen Makinelerde Eksenel Kaçıklık ve Dengesizliğin Titreşim Analizi. Bilecik Şeyh Edebali Üniversitesi Fen Bilimleri Dergisi , 7 (), 263-275 . DOI: 10.35193/bseufbd.669289.

[21] Kam, M., \& Saruhan, H. (2019). Kriyojenik işlem uygulanmış millerin yuvarlanmalı ve kaymalı yataklarda deneysel titreşim analizi. Politeknik Dergisi, 22(1), 129-134.

[22] Saruhan, H., \& Kam, M. (2016). Experimental spectral analysis of split sleeve bearing clearance effect on a rotating shaft system. Makine Teknolojileri Elektronik Dergisi, 13(4), 1-8. 